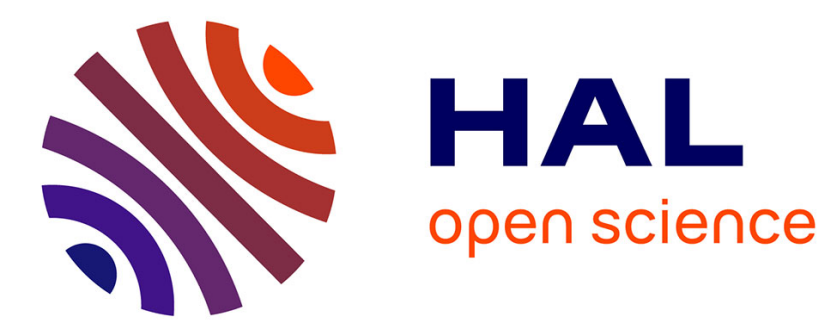

\title{
Terahertz imaging for subsurface investigation of art paintings
}

\author{
A. Locquet, Junliang Dong, Marcello Melis, David S Citrin
}

\section{To cite this version:}

A. Locquet, Junliang Dong, Marcello Melis, David S Citrin. Terahertz imaging for subsurface investigation of art paintings. SPIE Optical Engineering + Applications,, Aug 2017, San Diego, United States. pp.25, 10.1117/12.2274292 . hal-03084843

\section{HAL Id: hal-03084843 https://hal.science/hal-03084843}

Submitted on 21 Dec 2020

HAL is a multi-disciplinary open access archive for the deposit and dissemination of scientific research documents, whether they are published or not. The documents may come from teaching and research institutions in France or abroad, or from public or private research centers.
L'archive ouverte pluridisciplinaire HAL, est destinée au dépôt et à la diffusion de documents scientifiques de niveau recherche, publiés ou non, émanant des établissements d'enseignement et de recherche français ou étrangers, des laboratoires publics ou privés. 


\title{
Terahertz imaging for subsurface investigation of art paintings
}

\author{
A. Locquet*a,b J. Dong ${ }^{\mathrm{a}, \mathrm{b}}$, M. Melis ${ }^{\mathrm{c}}$, and D. S. Citrin ${ }^{\mathrm{a}, \mathrm{b}}$ \\ ${ }^{a}$ Unité Mixte Internationale 2958 Georgia Tech-CNRS, Georgia Tech Lorraine, \\ 2 Rue Marconi, 57070 Metz, France \\ ${ }^{\mathrm{b}}$ School of Electrical and Computer Engineering, Georgia Institute of Technology, \\ 30332-0250, Atlanta, Georgia, USA \\ 'Profilocolore srl, Via Spluga, 2200141 Roma, Italy
}

\begin{abstract}
Terahertz (THz) reflective imaging is applied to the stratigraphic and subsurface investigation of oil paintings, with a focus on the mid-20th century Italian painting, 'After Fishing', by Ausonio Tanda. THz frequency-wavelet domain deconvolution, which is an enhanced deconvolution technique combining frequency-domain filtering and stationary wavelet shrinkage, is utilized to resolve the optically thin paint layers or brush strokes. Based on the deconvolved terahertz data, the stratigraphy of the painting including the paint layers is reconstructed and subsurface features are clearly revealed. Specifically, THz C-scans and B-scans are analyzed based on different types of deconvolved signals to investigate the subsurface features of the painting, including the identification of regions with more than one paint layer, the refractive-index difference between paint layers, and the distribution of the paint-layer thickness. In addition, THz images are compared with X-ray images. The THz image of the thickness distribution of the paint exhibits a high degree of correlation with the X-ray transmission image, but $\mathrm{THz}$ images also reveal defects in the paperboard that cannot be identified in the X-ray image. Therefore, our results demonstrate that $\mathrm{THz}$ imaging can be considered as an effective tool for the stratigraphic and subsurface investigation of art paintings. They also open up the way for the use of non-ionizing $\mathrm{THz}$ imaging as a potential substitute for ionizing $\mathrm{X}$-ray analysis in nondestructive evaluation of art paintings.
\end{abstract}

Keywords: Terahertz imaging, terahertz time-domain spectroscopy, art painting, stratigraphic analysis.

\section{INTRODUCTION}

Terahertz time-domain spectroscopy (THz TDS) provides a nondestructive and noncontact technique for characterizing materials. THz waves can penetrate a variety of nonpolar materials which are opaque in the range of visible and infrared light. $\mathrm{THz}$ imaging can provide information in depth to investigate works of art, which is of great interest for conservation and restoration, as well as for art-historical studies. In recent years, THz imaging has shown great potential in the cultural-heritage arena [1-8]. In particular, $\mathrm{THz}$ has been successful in identifying features hidden under the surface of a painting, such as the artist's signature [9] or under-drawings [10-13]. Even in the case in which no underdrawing is present, identifying the stratigraphic structure of an art painting is useful in the study of the painter's technique.

The objective of this study is to apply to apply THz reflective imaging to reveal the stratigraphy and hidden features of a mid- $20^{\text {th }}$ century Italian oil painting on paperboard, After Fishing, by Ausonio Tanda, represented in Fig. 1, with it X-ray transmission image. The approach relies on the reconstruction of the structure of the painting based on the monitoring of the $\mathrm{THz}$ echoes resulting from the encountered interfaces. While the interface between the paint and the substrate of the painting can usually be identified, it is significantly harder to resolve the stratigraphy of the paint layers since the thickness of each paint layer or brushstroke may be tens of microns of even smaller. As a result, the measured reflected terahertz signal will usually contain multiple overlapping echoes and be complex to interpret. As explained in the next section, we employ the technique of frequency-wavelet domain deconvolution to resolve the echoes.

*alocquet@georgiatech-metz.fr 

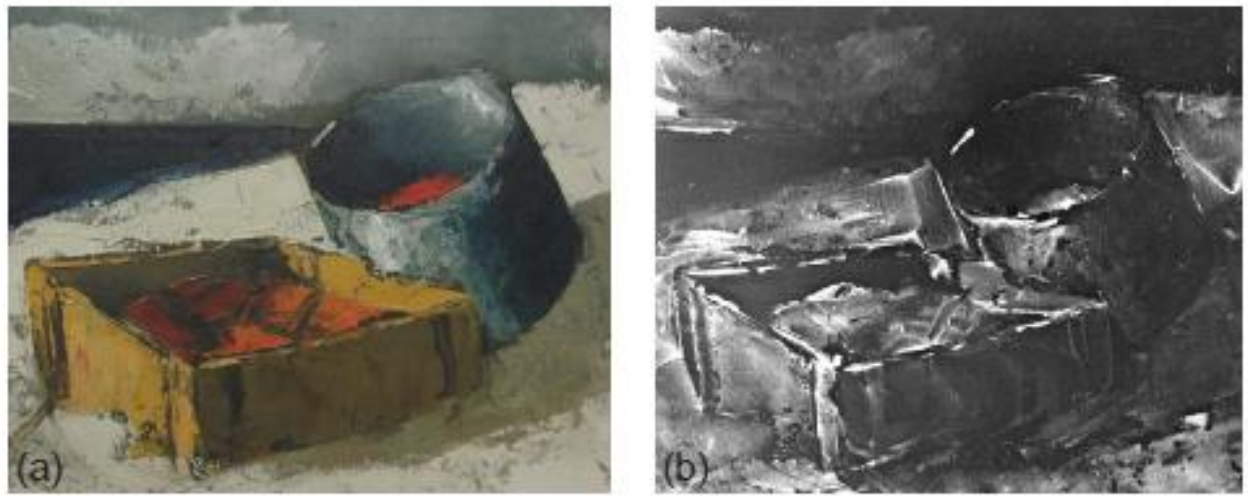

Figure 1.(a) Visible photograph of After Fishing and (b) X-ray transmission image. After Fishing is not copyrighted. Marcello Melis is the owner of After Fishing.

\section{FREQUENCY-WAVELET DOMAIN DECONVOLUTION}

The objective of terahertz deconvolution is to retrieve the impulse response of the system under study which, in a stratified system, should ideally consist of a sequence of ideal impulses corresponding to reflections from the interfaces. In a basic approach, the impulse response could be retrieved from the inverse Fourier Transform of the transfer function. The approach of frequency-wavelet domain deconvolution (FWDD) is to improve the deconvolution process by first employing frequency-domain filtering and then further increasing the signal-to-noise ratio by employing wavelet denoising techniques. In our work, the filtering is implemented by a Hanning window with a cutoff frequency which is typically of $4 \mathrm{THz}$. Often, the obtained deconvolved signal does not present a satisfactory SNR when a large cutoff frequency is employed. Stationary wavelength shrinkage is employed to further reduce the SNR. Wavelet coefficients with small absolute values are considered as corresponding to noise and are disregarded. The signal reconstructed on the basis of the contributions of large coefficients is expected to lead to a signal in which the contribution of noise has been reduced. In our work, modified versions of the Daubechies wavelets have been employed. Additional technical details on the implementation of FWDD can be found in Ref. [14].
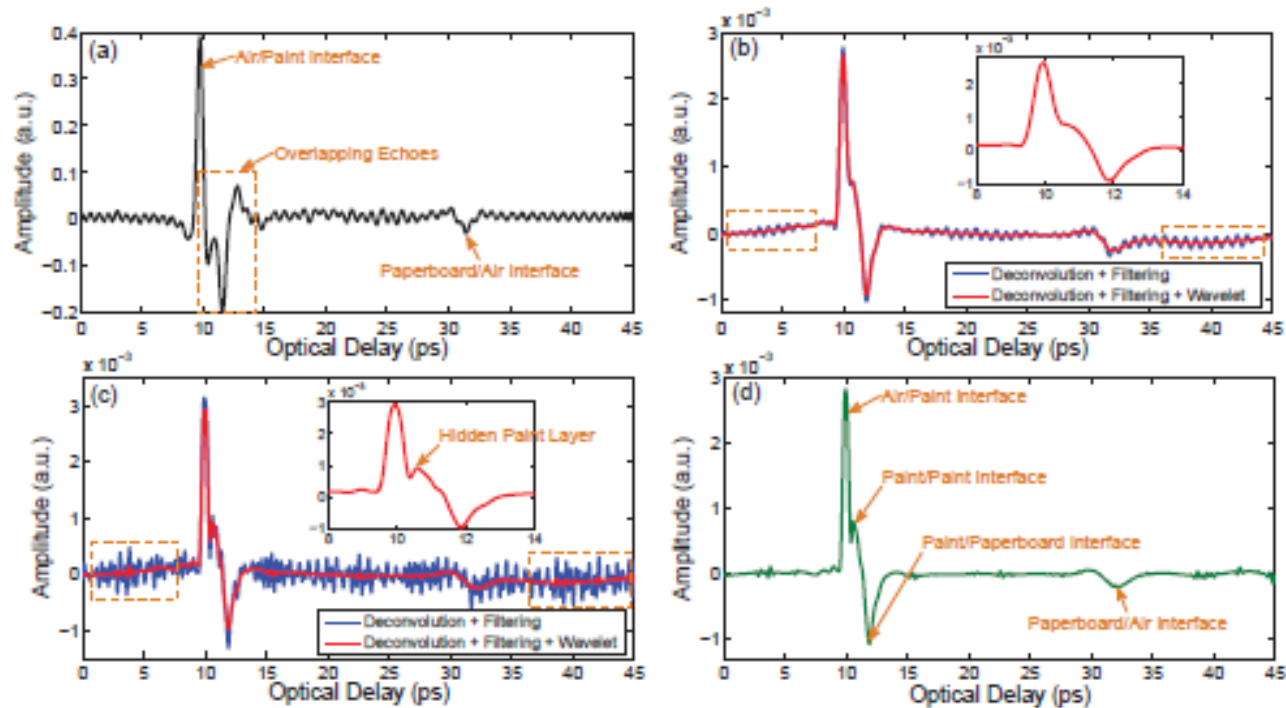

Figure 2. (a) Raw THz reflected waveform from a typical pixel. Deconvolved signal with $f_{C}=2 \mathrm{THz}$ (b), and $f_{C}=3 \mathrm{THz}$ (c). The final deconvolved signal, after filtering, wavelet de-noising, and baseline subtraction is shown in (d). 
Figure 2(a) represents a typical waveform reflected from the painting. The top and bottom surfaces of the painting can be clearly identified, while overlapping echoes due to the structure of the painting can be observed right after the first peak. Figure 2(b) shows the signal after deconvolution employing a Hanning filter with a cutoff frequency $f_{C}=2 \mathrm{THz}$. While the SNR appears to be good, an additional peak that indicates an underlying paint layer is not well separated. With $f_{C}=3$ $\mathrm{THz}$, the hidden peak can be clearly identified, but the SNR is low (Fig. 2(c)). As shown in Fig. 2(d), the residual noise are attenuated with wavelet decomposition, using the symlet wavelets and the final deconvolved waveform clearly exhibits one underlying paint layer or brushstroke at this single pixel.

\section{RESULTS AND DISCUSSION}

A THz TDS system was employed to raster-scan the painting with a set of motorized stages moving in the $X$ and $Y$ directions with a $1 \mathrm{~mm}$ spatial step over a $28 \mathrm{~cm} * 25 \mathrm{~cm}$ region of the painting, corresponding to $280 * 250$ pixels. Each recorded reflected $\mathrm{THz}$ waveform contains 4096 data points, and each pixel corresponds to an averaging over 10 shots.

Figures 3 (a-d) show THz C-scans in the frequency domain, using as a contrast mechanism the power spectral density at 0.4, 0.6, 0.8, and 1.2 THz, respectively. Higher frequency is helpful to observe smaller, more subtle, features. As we progress from Fig. 3(a) to Fig. 3(d), a ripple pattern appears in the upper left region The periodicity of the ripples is about $0.25 \mathrm{~mm}$, which corresponds approximately to the wavelength at $1.2 \mathrm{THz}$. We conclude that the ability to see the ripples is due to the increased resolution provided at the higher frequency and that the SNR is still sufficient at that frequency $(1.2 \mathrm{THz})$.

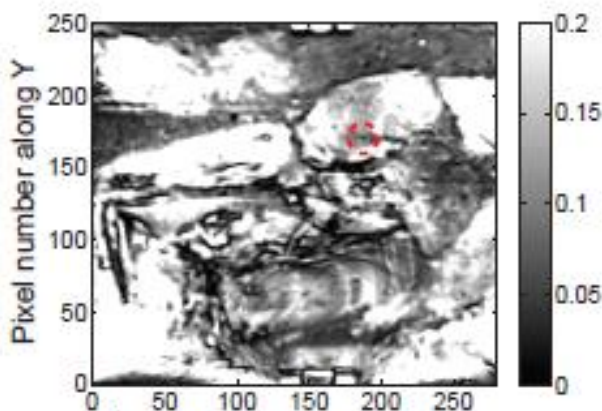

(a) Pixel number along $X$

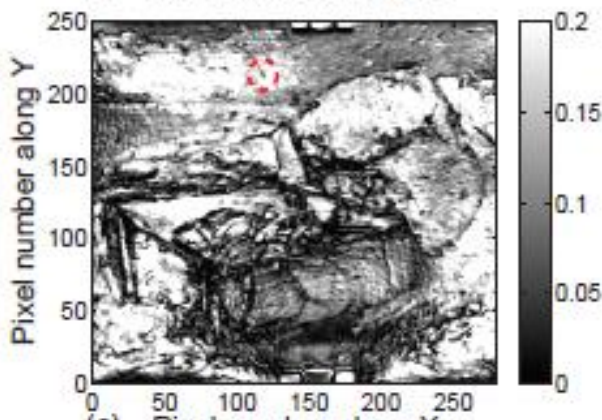

(c) Pixel number along $X$

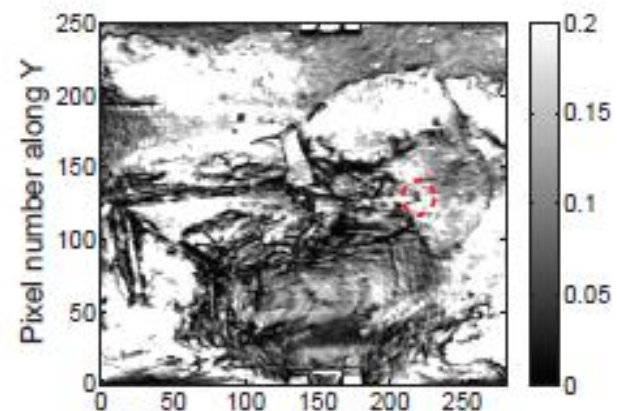

(b) Pixel number along $\mathrm{X}$

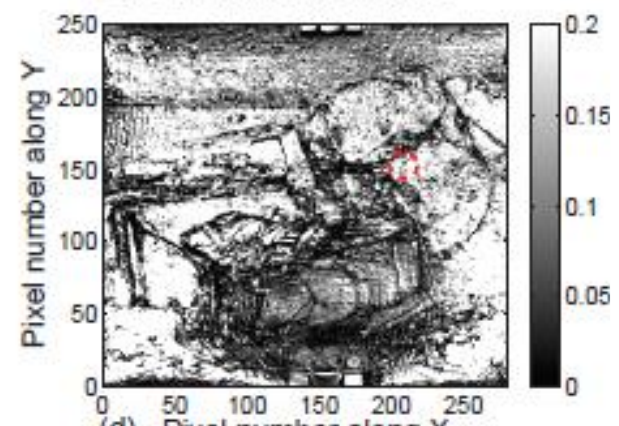

(d) Pixel number along $X$

Figure 3. C-scan images based on the raw data at in frequency domain at (a) 0.4 , (b) 0.6 , (c) 0.8 , and (d) $1.2 \mathrm{THz}$.

In addition, we can observe in Fig. 3 several small and blurred spots that seem to be randomly distributed and moreover, that do not appear in the X-ray image (Fig. 1(b)). The careful examination of the waveforms at the relevant pixels reveals that small echoes can be observed in the time intervals [12 ps, $28 \mathrm{ps}$ ], corresponding to the paperboard. These spots thus corresponds to defects in the paperboard, which we speculate may be due to oil and/or biological growth since organic materials can exhibit low radiological contrast and are thus difficult to visualize with X-ray-based methods. 
Though defects within the paperboard can be located on the basis of the raw signal, the inner characteristics of the much thinner paint layer cannot be directly determined based on this signal. FWDD is thus applied to all the pixels of the painting, with a cutoff frequency $f_{C}=3 \mathrm{THz}$, and 4 types of signals, represented in Fig. 4 , are observed after this deconvolution method is applied. For type I, shown in Fig.4 (a), a small peak occurs before the main peak corresponding to the air/paint interface. The small peak reveals the presence of a rough surface (on the scale of a few hundred microns), leading portions of the $\mathrm{THz}$ beam to be reflected earlier than others. Figure 5(a) represents the $\mathrm{C}$-scan based on the amplitude of the precursor peak, while Fig. 5(b) is based on the dominant peak. Fig. 5(a) clearly reveals the outline of the objects in the foreground, for which the paint contains sharp angles, while Fig. 5(b) is a complimentary image to 5(a), confirming that the $\mathrm{THz}$ reflected energy is spread among the first and second peaks. For type II and III, one additional peak is detected between the air/paint and the paint/paperboard interfaces, indicating the presence of an additional paint layer or brushstroke. For type II, the additional peak is positive, indicating that the additional layer has a larger refractive index than that of the surface peaks. The additional peak is negative for type III, showing that the additional paint has a lower refractive index. THz B-scans can be reconstructed based on the deconvolved signals to reveal the stratigraphy of the painting. Figure 6 shows B-scans, based on the raw and deconvolved data, for two cross-sections corresponding to regions where type III and II waveforms are dominant. The scans based on the deconvolved data clearly reveal the stratigraphy of the painting and, specifically, the presence of an additional paint layer.
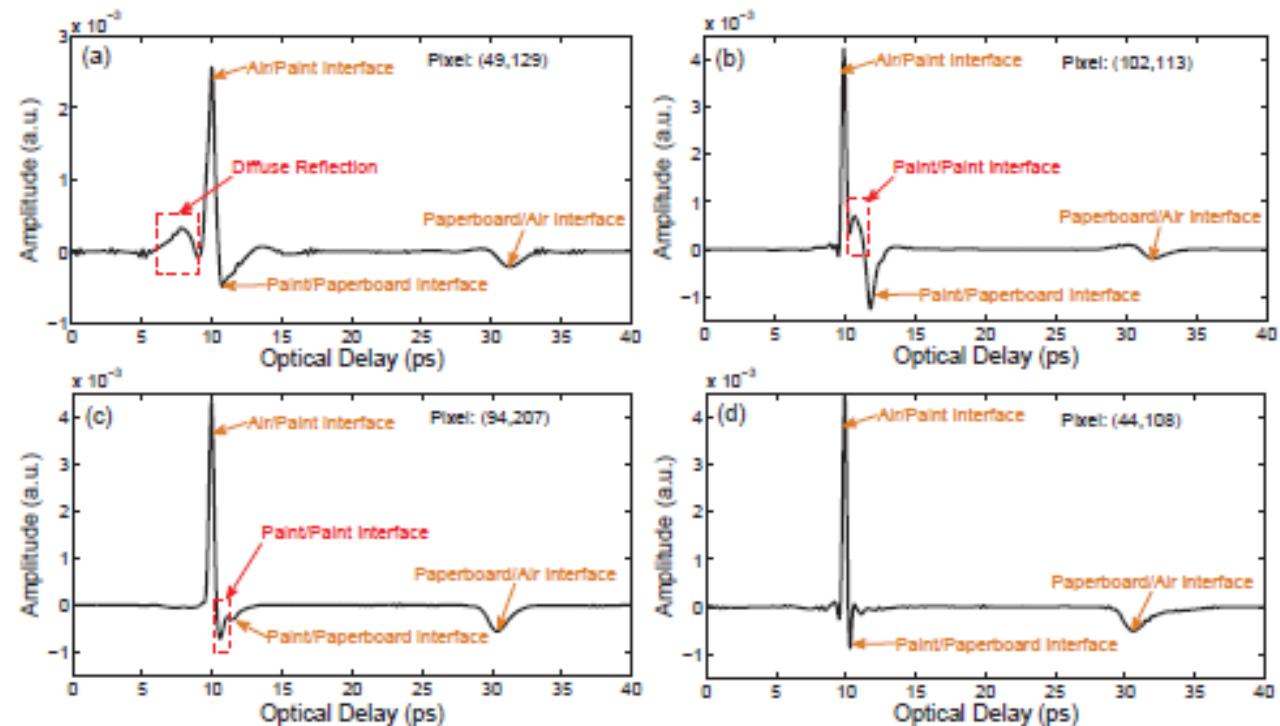

Figure 4. Four different types of deconvolved signals. C-scan images based on the raw data at in frequency domain at (a) 0.4 , (b) 0.6 , (c) 0.8 , and (d) $1.2 \mathrm{THz}$.
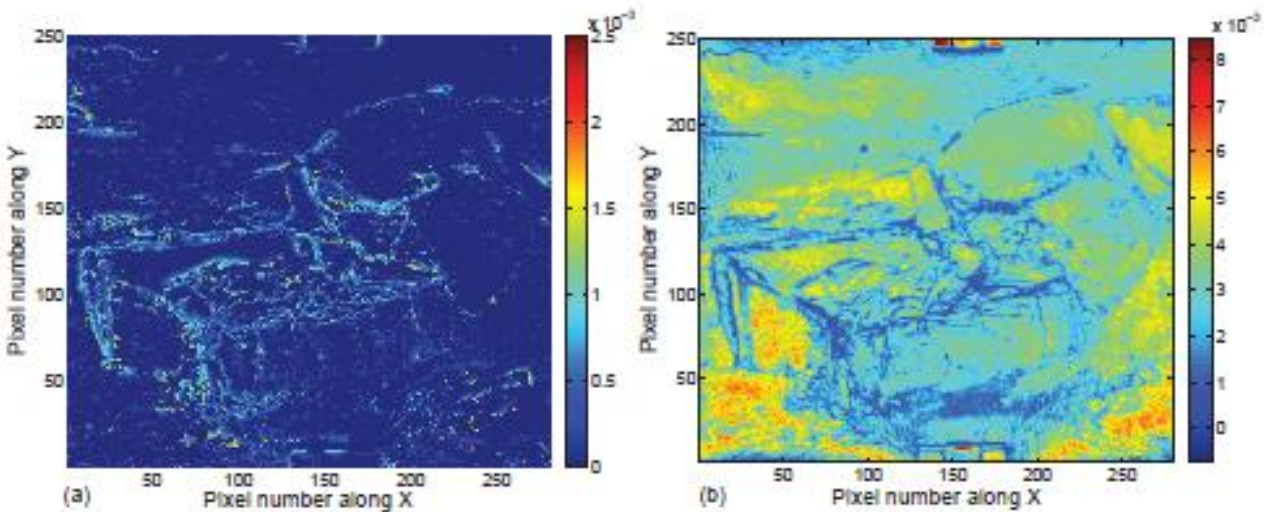

Figure 5. THz C-scans for type-I signals, based on (a) the amplitude of the precursor peak and (b) the amplitude of the main peak. 

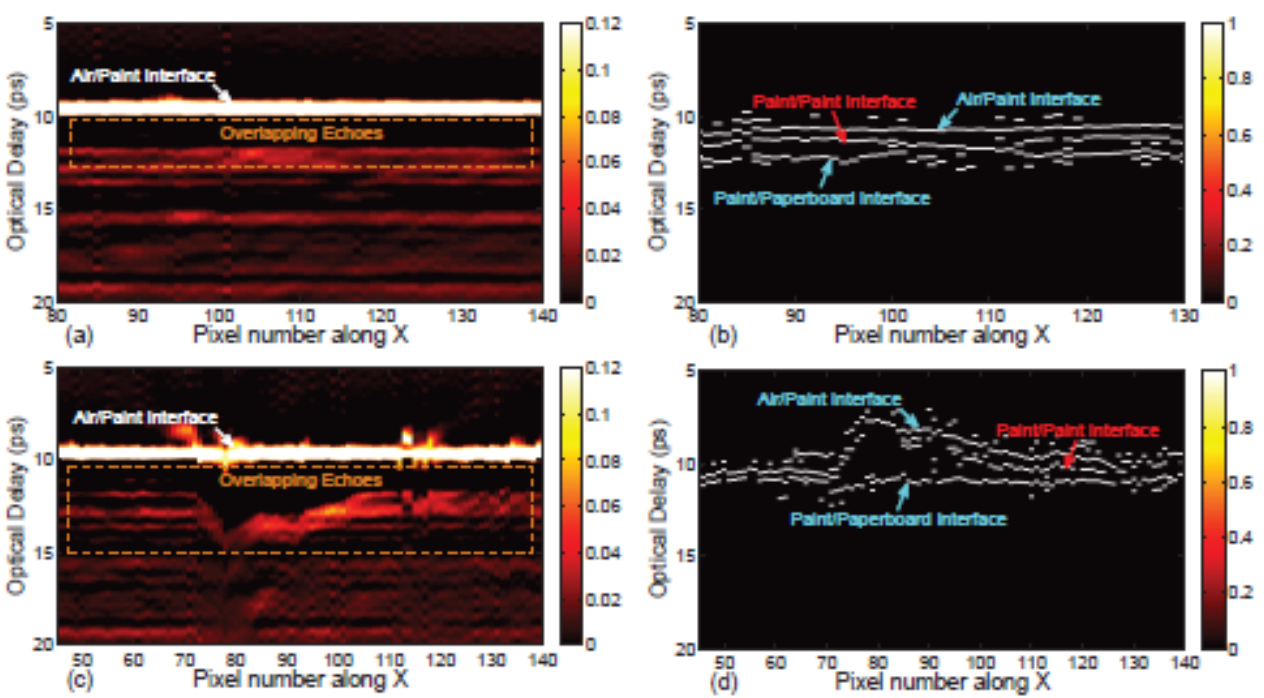

Figure 6. Comparing THz B-scans based on the raw and deconvolved data. (a),(b) correspond to a cross-section of the painting where type-III signals are dominant, while (c),(d) refer to a cross-section where type-II signals are dominant. (a),(c) are based on the raw data, while (c),(d) are binary B-scans based on the deconvolved data..

Finally, in the case of type IV waveforms, shown in Fig. 4(d), no additional peak or feature can be identified from the deconvolved data, implying that the surface is probably flat and that no additional paint layer can be detected.

\section{CONCLUSION}

Terahertz pulsed imaging has been employed to analyze a mid- $20^{\text {th }}$ century Italian oil painting on paperboard. The raw reflected data can be used to reveal the presence of possibly organic inclusions in the paperboard but fails to reveal the stratigraphy of the paint. By applying frequency-wavelet domain deconvolution to the raw data, 4 distinct types of reflected waveforms can be identified. We have shown that these deconvolved waveforms contain important information revealing in particular the outline of the painting and the presence of an additional paint layer. We conclude that $\mathrm{THz}$ frequency-wavelet domain deconvolution is a useful tool for the surface and sub-surface investigation of art paintings or of other stratified systems.

\section{ACKNOWLEDGMENTS}

A.L, J.D., and D.S.C thank the financial support of the Fonds Européen de Développement Régional and the Conseil Régional Grand Est.

\section{REFERENCES}

[1] J. B. Jackson, J. Bowen, G. Walker, J. Labaune, G. Mourou, M. Menu, and K. Fukunaga, “A survey of terahertz applications in cultural heritage conservation science," IEEE Trans. THz Sci. Technol. 1, 220-231 (2011).

[2] K. Krügener, M. Schwerdtfeger, S. F. Busch, A. Soltani, E. Castro-Camus, M. Koch, and W. Viöl, "Terahertz meetssculptural and architectural art: Evaluation and conservation of stone objects with T-ray technology," Sci. Rep. 5, 14842 (2015).

[3] M. Koch, S. Hunsche, P. Schumacher, M. C. Nuss, J. Feldmann, and J. Fromm, "THz-imaging: a new method for density mapping of wood," Wood Sci. Technol. 32, 421-427 (1998). 
[4] J. B. Jackson, M. Mourou, J. Labaune, J. F. Whitaker, I. N. Duling III, S. L.Williamson, C. Lavier, M. Menu, and G.A. Mourou, "Terahertz pulse imaging for tree-ring analysis: a preliminary study for dendrochronology applications," Meas. Sci. Technol. 20, 075502 (2009).

[5] J. Labaune, J. B. Jackson, K. Fukunaga, J. White, L. D’Alessandro, A. Whyte, M. Menu, and G. Mourou, "Investigation of Terra Cotta artefacts with terahertz," Appl. Phys. A 105, 5-9 (2011).

[6] J. Labaune, J. B. Jackson, S. Pagès-Camagna, I. N. Duling III, M. Menu, and G. A. Mourou, "Papyrus imaging with

terahertz time domain spectroscopy,” Appl. Phys. A 100, 607-612 (2010).

[7 ] L. Öhrström, B. M. Fischer, A. Bitzer, J. Wallauer, M. Walther, and F. Rühli, "Terahertz imaging modalities of ancient Egyptian mummified objects and of a naturally mummified rat," The Anatomical Record 298, 1135-1143 (2015).

[8] J. B. Jackson, J. Labaune, R. Bailleul-Lesuer, L. D’Alessandro, A. Whyte, J. W. Bowen, M. Menu, and G. Mourou,"Terahertz pulse imaging in archaeology," Frontiers of Optoelectronics 8, 81-92 (2015).

[9] C. Seco-Martorell, V. López-Dominguez, G. Arauz-Garofalo, A. Redo-Sanchez, J. Palacios, and J. Tejada, "Goya's

artwork imaging with Terahertz waves,” Opt. Express 21, 17800-17805 (2013).

[10] C. L. Koch-Dandolo, T. Filtenborg, K. Fukunaga, J. Skou-Hansen, and P. U. Jepsen, "Reflection terahertz time domain imaging for analysis of an 18th century neoclassical easel painting," Appl. Opt. 54, 5123-5129 (2015).

[11] C. L. Koch-Dandolo, T. Filtenborg, J. Skou-Hansen, and P. U. Jepsen, “Analysis of a seventeenth-century panelvpainting by reflection terahertz time-domain imaging (THz-TDI): contribution of ultrafast optics to museum collections inspection," Appl. Phys. A 121, 981-986 (2015).

[12] C. L. Koch-Dandolo, and P. U. Jepsen, "Wall painting investigation by means of non-invasive terahertz timedomain imaging (THz-TDI): Inspection of subsurface structures buried in historical plasters," J. Infrared Millim. Te. 37, 198-208 (2016).

[13] K. Fukunaga, T. Ikari, and K. Iwai, "THz pulsed time-domain imaging of an oil canvas painting: a case study of a painting by Pablo Picasso," Appl. Phys. A 122, 106 (2016).

[14] J. Dong, J.B. Jackson, M. Melis, D. Giovanacci, G.C. Walker, A. Locquet, J.W. Bowen, and D.S. Citrin, "Terahertz frequency-wavelet domain deconvolution for stratigraphic and subsurface investigation of art painting", Opt. Express 24, 26972 (2019). 